\title{
BUSCANDO SIGNIFICADO NAS EXPERIENCIAS VIVIDAS PELA PROFESSORA GRACITA GRUBER MARCONDES
}

\author{
LOOKING FOR SIGNIFICANCE IN EXPERIENCES LIVED BY TEACHER GRACITA \\ GRUBER MARCONDES
}
BUSCANDO SIGNIFICADO EN LAS EXPERIENCIAS VIVIDAS POR LA PROFESORA GRACITA GRUBER MARCONDES

Edenir Pacheco*

edenir@unicentro.br

\author{
Alboni Marisa Dudeque Pianovski Vieira ${ }^{* *}$ \\ alboni@alboni.com
}

\begin{abstract}
REVISTA PEDAGÓGICA
Revista do Programa de Pós-graduação em Educação da Unochapecó | ISSN 1984-1566

Universidade Comunitária da Região de Chapecó | Chapecó-SC, Brasil

Como referenciar este artigo: PACHECO, E.; VIEIRA, A. M. D. P. Buscando significado nas experiências vividas pela professora Gracita Gruber Marcondes. Revista Pedagógica, Chapecó, v. 18, n. 38, p. 239-254, maio/ago. 2016.

DOI: http://dx.doi.org/10.22196/rp.v18i38.3397
\end{abstract}

\begin{abstract}
RESUMO: Esse estudo tem como objetivo compreender o significado das experiências de Gracita Gruber Marcondes por meio de sua história de vida. Trata-se de uma pesquisa qualitativa, com uso de narrativas, por meio da história oral. Para isso, realizam-se entrevistas presenciais e analisaram-se fontes documentais e um livro de autoria da entrevistada. A responsabilidade em registrar e dar sentido à história de Guarapuava pela historiadora institui-se na forma de reunir em acervo particular de fotografias, livros, revistas, jornais e documentos, e sua dedicação demasiada ao ensino, tendo em vista que uma aula ministrada não é simplesmente um repasse de conteúdo, visto que enfatiza que o conteúdo apresentado aos alunos dever ser acompanhado de uma história, como maneira de dar significado ao que está sendo proposto. Nesse sentido, a professora Gracita contribuiu para que a história da memória da cidade de Guarapuava fosse preservada.
\end{abstract}

Palavras-chave: História de Vida de Professor. Memórias do Professor. História Oral.

\footnotetext{
ABSTRACT: This study aims to understand the meaning of Gracita Gruber Marcondes's experiences through thestory of her life. This is a qualitative research using narratives through oral history. For this, face interviews were conducted and documentary sources and a book written by the interviewee were analysed. The responsibility to record and make sense of Guarapuava history by Gracita established in the form of gathering in private collection of photographs, books, magazines, newspapers and documents. Her dedication in teaching
}

was relevant, in order that a given class is not simply a transfer of content, however, emphasizes that the story must accompanied the content presented to students, as a way to give meaning to what is being proposed. In this sense, Gracita teacher has contributed to the preservation of the history of the city of Guarapuava.

Keywords: Teacher's life story, Professor's Memories, Oral History.

RESUMEN: Este estudio tiene como objetivo comprender el significado de las experiencias de Gracita Gruber Marcondes a través de su historia de vida. Se trata de una investigación cualitativa, utilizando narrativas, a través de la historia oral. Para eso se llevaron a cabo entrevistas presenciales y fuentes documentales analizadas y un libro escrito por la entrevistada. La responsabilidad de registrar y dar sentido a la historia de Guarapuava por la historiadora se establece reuniendo una colección privada de fotografías, libros, revistas, periódicos y documentos, y su gran dedicación a la enseñanza, considerando que una clase dada no es simplemente una transferencia de contenido, y si, hace hincapié en que el contenido que se presenta a los estudiantes debe ir acompañado de una historia, como una forma de dar significado a lo que se propone. En este sentido, la profesora Gracita contribuyó a que la historia de la memoria de la ciudad de Guarapuava sea conservada.

Palabras clave: Historia de Vida de Profesor. Memórias del Profesor. Historia Oral. 
* Mestre em Educação da Pontifícia Universidade Católica do Paraná (PUC-PR). Técnica em Assuntos Universitários da Universidade Estadual do Centro-Oeste (UNICENTRO), em Guarapuava, Paraná.

\footnotetext{
${ }^{* *}$ Doutora em Educação pela Pontifícia Universidade Católica do Paraná (PUC-PR). Mestre em Educação pela PUC-PR. Mestre em Gestão de Instituições de Educação Superior pela Universidade Tuiuti do Paraná (UTP). Professora do Programa de Pós-Graduação em Educação da PUC-PR.
}

\section{INTRODUÇÃO}

A compreensão da história de vida do profissional da educação por meio da história oral possibilita olhar o docente como um sujeito vivo e dinâmico dentro do cenário educacional. Nessa linha de pensamento, a memória humana pode ser considerada como uma propriedade de conservação de informação.

A história oral tem relação com a abordagem biográfica, tradição oral e memória. Thompson (1992) defende que, apesar de existir uma semelhança entre autobiografia e história oral, a história oral tem uma amplitude maior. A narrativa do conjunto de experiências de vida de uma pessoa é tratada pela história oral, e o entrevistado tem autonomia para falar sobre sua história de vida.

As publicações da revista Annales, na década de 1920, fundada pelos historiadores Marc Bloch e Lucien Febvre, da Universidade de Estrasburgo, deram destaque à história oral. A criação da revista Annales foi um marco na busca de novos objetos e tinha como uma de suas características principais o uso da interdisciplinaridade, reunindo e relacionando em suas edições aspectos da história cultural (THOMPSON, 1992).

A história oral evoca a percepção do passado como algo que tem continuidade no presente, e permite sentido social à vida das pessoas, que precisam entender a sequência histórica e participar desse contexto em que vivem. A presença do passado no presente das pessoas é a razão de ser da história oral, que, por sua vez, é sempre uma história do "tempo presente" sendo reconhecida como história viva (LIMA; GUALDA, 2001).

O ponto central deste estudo é compreender o período de atuação da historiadora Gracita Gruber Marcondes, que, o longo de sua vida, dedicou-se como professora, historiadora e autora de livros, identificando o percurso e aspectos de sua prática pedagógica.

Contar a história de vida de Gracita é abrir a porta de um cenário que revela experiências e significados na sua carreira profissional, porque imprime marcas indeléveis de lembranças como professora primária, secundária e universitária e, também, por proporcionar aos alunos a oportunidade de aprenderem sobre a história do Brasil de uma forma contextualizada e prazerosa. Assim, tem-se o seguinte questionamento: como identificar o percurso de vida e aspectos de sua prática pedagógica?

Objetiva-se responder tal problema de pesquisa pela compreensão da história de vida de Gracita, utilizando-se a metodologia da história oral. Como explica Alberti (2005), ao relatar sobre a vida pessoal, as pessoas se sentem mais à vontade para falar sobre suas experiências e interpretar o passado, reavaliando inclusive suas posições e atitudes, como uma espécie de balanço da própria vida.

A escolha do tema é uma forma de compartilhar as experiências de vida e de trabalho, que pode fornecer 
dados em relação ao modo como os professores constroem sua vida profissional, pois quando um local não possui registro de sua história, a sua identidade e o seu significado se tornam vagos e frágeis. Portanto, é válido e essencial que esses registros sejam mantidos - tais como livros, documentos, entre outros -, para facilitar a construção e a reconstrução da história, com vistas ao desenvolvimento cultural e educacional de uma nação. Nesse sentido, identificar e compreender o significado das experiências de Gracita Gruber Marcondes, que atuou de forma relevante entre 1938 a 2010, no estado do Paraná, mais especificamente na cidade de Guarapuava, não somente pode permitir que docentes e discentes tomem conhecimento acerca de suas obras publicadas - conhecendo a história de Guarapuava e suas contribuições -, como também estimular a reflexão no contexto em que vivem e atuam.

\section{HISTÓRIA CULTURAL E HISTÓRIA ORAL}

A história cultural tem como principal objetivo identificar o modo como uma determinada realidade social é construída, pensada, e compreendida em diferentes lugares e momentos (CHARTIER, 1990). Por meio da história cultural, é possível entender como se desenvolveram e se construíram atividades pelos professores que se dedicaram a uma sociedade. E como exemplo disso, Julia (2001) relata sobre uma pesquisa realizada com 4.000 professores primários franceses da Terceira República na década de 1960, e que tinham exercido a sua profissão antes da primeira Guerra Mundial. Essa pesquisa demonstrou que esses professores eram oriundos de meios modestos (por exemplo, artesões, camponeses e comerciantes), que seus pais - nascidos por volta de 1850 - eram mais alfabetizados do que outras categorias sociais, e que havia o desejo compartilhado pela escola entre pais e filhos que permitiu a ascensão social em direção à profissão do professor primário (JULIA, 2001, p. 18).

Nesse processo, os professores acabaram reinventando a história social, o que contribui para os argumentos de Chartier (1990), quando relata que é possível compreender as práticas que constroem o mundo como representação. Thompson (1992) também valoriza as pessoas comuns que procuram compreender a história por meio das mudanças que ocorrem na própria vida e, em especial, a história da família, que pode dar ao indivíduo um forte sentimento de vida mais longa por meio da história local ou da cidade, quando se busca sentido para a sua própria natureza em mudança. Isso contribui para que outras pessoas adquiram uma percepção das raízes pelo conhecimento pessoal da história cultural.

Dessa forma, Thompson (1992) ressalta o valor da história de vida das pessoas, e especificamente da história oral, que pode dar grande contribuição ao resgate da memória. Esse autor enfatiza a necessidade de preservar a 
memória física e espacial, pois a memória de uma pessoa pode significar a memória de pessoas, possibilitando a evidência dos fatos coletivos. E, para isso, a história oral possibilita novas dimensões da história ao dar voz a múltiplos e diferentes narradores. Esse tipo de projeto propicia, sobretudo, fazer da história uma atividade mais democrática, a cargo das próprias comunidades, permitindo construir a história a partir das próprias palavras daqueles que vivenciaram e participaram de um determinado período.

Na visão de Le Goff (2003), é possível obter esse canal de comunicação entre o passado e o presente, por meio das experiências humanas, havendo uma função social da história. A memória humana pode ser considerada como uma propriedade de conservação de informação. Essas "[...] informações remetem em primeiro lugar ao conjunto de funções psíquicas, graças às quais o homem pode atualizar impressões ou informações passadas, ou que ele representa passadas" (LE GOFF, 2003, p. 419).

Em conformidade com Nóvoa (1995), é necessário compreender como cada pessoa se formou e encontrar as relações de pluralidades que cada uma atravessa na vida, pois ninguém se forma no vazio. Para tanto, é essencial ter acesso ao modo como cada pessoa se especializou e ter em mente a singularidade de sua história de vida, que vai além do modo singular como age, reage e interage no seu contexto.

Esses pressupostos teóricos contribuem para compreender e confrontar com a história de vida que é objeto deste artigo.

\section{METODOLOGIA}

Este estudo tem como objetivo compreender o significado das experiências de Gracita Gruber Marcondes, por meio de sua história de vida. É possível ter acesso a essa complexidade a partir da identificação de processos parciais de formação enquanto componentes e traços dominantes de uma história de vida. Para isso, realizam-se entrevistas presenciais e analisaram-se fontes documentais e um livro de autoria da entrevistada.

Trata-se de uma pesquisa qualitativa, com uso de narrativas, por emprego da história oral. A escolha do entrevistado é outro ponto crucial, já que o processo de seleção do entrevistado em uma pesquisa de história oral precisa ter concordância com a unidade qualitativa, o tema estudado e o papel estratégico para responder ao problema de pesquisa (ALBERTI, 2005). E a escolha pela professora Gracita atende a essas especificações.

\section{MOMENTOS DE UMA HISTÓRIA DE VIDA}

Nesta seção, a trajetória e relatos da vida de Gracita Gruber Marcondes são apresentados. 


\subsection{Início da trajetória}

Gracita Amaral Gruber (seu nome de batismo), nasceu no dia 21 de abril de 1924 em Irati no Paraná, e passou a se chamar Gracita Gruber Marcondes após seu casamento com Norberto Marcondes. Os pais se chamavam Alcides Gruber e Olympia Amaral Gruber. Gracita é a terceira filha de 11 irmãos.

Os pais eram naturais de Curitiba/PR; após se casarem, foram residir na Colônia Itapará, distrito de Irati/PR, uma colônia de imigrantes poloneses e ucranianos. Nesse local, o pai de Gracita tornou-se comerciante e exportador de erva-mate cancheada produzida em seus barbaquás, que se situavam em Papagaios, Cerro do Leão e Inácio Martins.

Olympia, mãe de Gracita, que era professora normalista formada pela segunda turma da Escola Normal na cidade de Curitiba, teve os seguintes professores quando era aluna: Júlia Wanderley, Francisco Ribeiro de Macedo, Dario Vellozo, entre outros. Na Colônia Itapará, distrito de Irati, Olympia foi nomeada professora para as quatro séries do curso primário.

Gracita narra sobre os momentos difíceis que a sua família enfrentou:

A partir do ano de 1929, quando iniciou a grande crise - que, em 1930, também atingiu o comércio da erva-mate-, meu pai teve grandes prejuízos que o levaram à falência. E, para que ele não ficasse com o "nome sujo" no comércio, vendeu as propriedades e todo o estoque da casa comercial, inclusive as balanças. E a família passou a contar só com o ordenado de professora de minha mãe. Para agravar a situação, a única escola de Itapará fechou por perseguição política, $e$ minha mãe não recebeu oito meses de vencimentos, porque o inspetor escolar, que era concorrente comercial e da oposição política de meu pai, não atestou os mapas da frequência de minha mãe, cujo documento era exigido naquela época [...], e minha família começou a passar necessidades.

Em consequência disso, em janeiro de 1935, a família mudou-se para a cidade de Irati, onde a mãe de Gracita assumiu uma turma no Grupo Escolar Duque de Caxias. Nessa mesma época, Gracita cursou a terceira e a quarta séries do primário, e mais dois anos do curso complementar na mesma cidade.

O início da carreira profissional de Gracita como professora ocorreu em 1938, pouco antes do início da Segunda Guerra Mundial. Devido à escassez de professores, a Prefeitura Municipal de Irati nomeou alguns alunos aprovados no referido curso complementar como professores, sem a maioridade de 18 anos, exigida pelo Governo de Estado do Paraná. 
Gracita comprova, por meio de documentos, o seu exercício nas funções de professora municipal, datados de maio de 1938 a dezembro de 1940, da Secretaria da Prefeitura Municipal de Irati. Assim, aos 14 anos de idade, assumiu o cargo como professora auxiliar em uma escola da periferia da cidade. Logo após esse exercício, foi nomeada pelo Interventor Manoel Ribas, pelo Decreto $\mathrm{n}^{0}$ 11.633, de 24 de julho de 1941, como professora contratada Letra "D", para trabalhar no Grupo Escolar da cidade de Pitanga/PR, inaugurado no mesmo ano.

Gracita conta que, quando o Ginásio Estadual Manoel Ribas, localizado na cidade de Guarapuava, foi autorizado a realizar o primeiro exame de licença ginasial, de acordo o artigo 91 da Lei Orgânica do Ensino Secundário, houve uma oportunidade para aqueles que não frequentaram o curso seriado. E ela explica que prestou esse exame em 1946, capacitando-se para cursar a Escola Normal Secundária e o Curso Técnico de Contabilidade, em Irati, onde assumiu uma classe de terceira série no Grupo Escolar Duque de Caxias.

Em 1950, formou-se nos cursos Normal Secundário e Técnico de Contabilidade, transferindo-se para a cidade de Guarapuava/PR, para lecionar na Escola de Aplicação Visconde de Guarapuava, onde atuou nas terceiras e quartas séries primárias. Em 1954, assumiu a Secretaria do Ginásio Manoel Ribas, onde passou a ministrar aulas de História Geral e História do Brasil, como professora suplementarista.

Para conseguir o registro definitivo, exigido na época para ministrar aulas no curso secundário, fez dois cursos de férias, em janeiro e fevereiro, promovidos pela Capacitação do Ensino Superior (CADES) para os professores do curso secundário que não possuíam curso superior. Gracita foi aprovada nesse exame de suficiência para lecionar História do Brasil e Geral, habilitando-se, inclusive, para prestar concurso em qualquer outra matéria. Esses cursos foram ministrados em Curitiba/PR, com professores da Universidade Federal do Paraná (UFPR) e outros, vindos do Colégio D. Pedro II, do Rio de Janeiro.

Com a posse do registro, Gracita prestou concurso para a disciplina de Fundamentos da Educação, realizado na cidade de Ponta Grossa/PR, sendo nomeada para trabalhar na Escola Normal Professor Amarílio, em Guarapuava/PR, em 1961. E exerceu esse cargo até sua aposentadoria em 1969.

Ainda em 1951, havia prestado concurso de provas e títulos, sendo aprovada e nomeada para exercer a profissão de professora no Ginásio Estadual Manoel Ribas em Guarapuava, nas disciplinas de História Geral e História do Brasil. No ano de 1994, aposentou-se dessa atividade.

\subsection{Atuação profissional}

A vida profissional de Gracita constitui-se de grande valia para os estudos e as pesquisas sobre a cidade de 
Guarapuava, considerando-se suas obras. O interesse pela história de Guarapuava é evidenciado por suas memórias e os interesses percebidos nas entrevistas, evidenciando valores que explicam sua identidade como professora e pesquisadora.

A dedicação e o compromisso em ensinar é algo nato da personalidade dessa professora. A responsabilidade social foi um dos objetivos para que os alunos aprendessem o conteúdo proposto em sala de aula.

Gracita relatou sobre a forma diferenciada que adotou para que os alunos obtivessem aproveitamento do conteúdo ministrado em sala de aula:

Iniciei as atividades docentes quando a estrutura do nosso país favoreceu a introdução da Escola Nova, que foi de 1930 a 1960. Devido à minha imaturidade e sem um curso superior, pouco sabia sobre a didática, mas fui orientada por minha mãe, que já era professora formada pela $2^{a}$ turma da Escola Normal de Curitiba. Naquele tempo, Anísio Teixeira, influenciado pelas ideias de John Dewey defendia uma escola pública mais democrática, gratuita, e extensiva a todas as camadas sociais para todos os níveis de ensino. Seria o progresso da sociedade, tendo professores capazes e competentes, para desenvolver os valores inatos, os talentos e as vocações do educando com responsabilidade moral e formar o futuro cidadão comprometido com a pátria e o semelhante. Anísio Teixeira pregava que era preciso ensinar, - antes dos conteúdos - a educação para a vida, a fraternidade e o amor cívico para com a pátria. Defendeu a valorização da escola e do professor, daí os pais ensinarem seus filhos que o professor teria de ser respeitado, porque estava preparando o seu futuro. Isto foi uma das razões de existirem tão poucos problemas disciplinares.

A entrevistada disse que se sente realizada pelos anos de magistério que foram de 1938 a 1994, por ter sido sempre respeitada e por se fazer respeitar, tratando a todos sem distinção e com muito carinho, motivos pelos quais nunca teve problemas disciplinares. Quando percebia que poderia haver algum problema, imediatamente dava uma responsabilidade para que o aluno se sentisse valorizado. Gracita fez questão de deixar claro que foi a sua criatividade que marcou as suas aulas, pois a maneira de prepará-las proporcionava uma forma de incentivo, sempre de acordo com os interesses da idade do educando. Isso produziu tão bons resultados que, posteriormente, adotou essa prática para as aulas ministradas aos acadêmicos.

Foi no ambiente escolar que Gracita se concebeu como historiadora. Ela relata como aconteceu: "[...] estava ministrando uma aula de história, há mais de 50 anos, 
quando uma aluna me fez uma pergunta: 'por que a cidade se chama Guarapuava?"'.

A entrevistada conta que no momento ficou muito envergonhada por não saber responder; então, teve a iniciativa de pesquisar sobre a questão levantada pela aluna, para devolver-lhe uma resposta. A pergunta da aluna a inquietou. E, a partir daquele momento, Gracitas interessou-se mais por questões históricas e iniciou a sua trajetória como pesquisadora e autora de vários livros. A professora Gracita relata sobre sua participação na criação da primeira instituição de ensino superior estadual na cidade de Guarapuava, que ocorreu na década de 1960:

Nós, os professores do Ginásio Manoel Ribas e a comunidade guarapuavana, havíamos nos mobilizado, pleiteando a criação de um estabelecimento de nível superior em Guarapuava. E, em 15 de julho de 1968, o Governador Paulo Pimentel criou a Faculdade de Filosofia Ciências e Letras de Guarapuava (FAFIG), hoje UNICENTRO, que iniciou suas atividades em 1970, com os cursos de Português, Matemática, História e Geografia. Cursei a turma pioneira do Curso de História; e, em 1980, já como professora licenciada prestei concurso, sendo lotada no Departamento de Ciências Humanas. Após, realizei inúmeros cursos de aperfeiçoamento e dois cursos de especialização: Metodologia do Ensino Superior e História Socioeconômica. Nesse estabelecimento de ensino, ministrei aulas de História Geral e do Brasil para o Curso de História; de Cultura Brasileira para o Curso de Letras; e História Econômica para os Cursos de Administração e Ciências Contábeis, aposentando-me compulsoriamente em 1994, por completar 70 anos de idade.

Outro momento considerado especial para Gracita foi quando recebeu uma homenagem, no dia 13 de novembro de 2007, pela renomada poetisa Naiade Ribeiro de Camargo, ex-aluna na época de sua atuação como professorado Grupo Escolar Duque de Caxias. É interessante ressaltar que, nesse local, a mãe da entrevistada também lecionou.

Estes são alguns trechos da homenagem prestada pelo “Jornal Folha de Irati” a Gracita:

[...] um misto de saudade e, ao mesmo tempo, um contentamento por poder vivenciar as coisas boas da vida. E quem tornou isso possível? Muitas pessoas deixaram marcas indeléveis em minha vida e me serviram de exemplo. Daquela época, gostaria de destacar e homenagear a professora Dona Gracita Gruber, que trabalhou, por muitos anos, no Grupo Escolar Duque de Caxias, e foi minha professora no terceiro ano. Nós os alunos, sentados aguardando a sua chegada. 
[...] Boa tarde, ela nos saudava sorridente [...]. Colocava a bolsa e os cadernos em cima da mesa, e começava a nos contar o filme que tinha assistido no Cinema do Wasilewski. As suas palavras criavam asas, os seus gestos pareciam nos abraçar e a sua voz nos levava a outros mundos. Naqueles momentos mágicos, recebíamos, também, o pó dourado do conhecimento.

Essas palavras proferidas pela poetisa Naia de $\mathrm{Ri}$ beiro de Camargo exprimem somente uma parte do texto publicado.

\subsection{Trabalhos realizados}

Gracita conta que, durante todo o tempo de trabalho ativo e mesmo dispondo de poucas horas, continuava pesquisando sobre a História de Guarapuava e publicando as obras de sua exclusiva autoria, conforme mostra o quadro a seguir:

Quadro 1 - Obras de Gracita Gruber Marcondes

\begin{tabular}{|l|c|}
\hline Obras & Ano de Publicação \\
\hline $\begin{array}{l}\text { 1. "A expansão campeira e a integração de Guarapuava } \\
\text { ao comércio de gado sulino". }\end{array}$ & 1983 \\
$\begin{array}{l}\text { 2. "A Igreja Católica em Guarapuava, antes e após a } \\
\text { criação da Diocese". }\end{array}$ & 1987 \\
$\begin{array}{l}\text { 3. "Guarapuava: história de luta e trabalho". } \\
\text { 4. "20o anos de uma caminhada histórica: } 1810- \\
\text { 2010". }\end{array}$ & 2010 \\
$\begin{array}{l}\text { 5. No prelo, o artigo: "Antecedentes Históricos - } \\
\text { Campos de Guarapuava: descoberta e início do } \\
\text { povoamento". }\end{array}$ & $* *$ \\
\hline
\end{tabular}

** Será publicado pela primeira revista da Associação dos Professores Aposentados (ADAU) da Universidade Estadual do Centro-Oeste (UNICENTRO).

Fonte: Dados da pesquisa (2014).

A autora tem uma enorme satisfação ao falar de sua obra "200 anos de uma caminhada histórica: 1810-2010", que contém 665 páginas e 37 capítulos, distribuídos conforme ilustra o seguinte quadro:

Quadro 2 - Informações do livro "200 anos de uma caminhada histórica: $1810-2010 "$

\begin{tabular}{|l|l|}
\hline Capítulos & Assuntos abordados \\
\hline $\begin{array}{l}\text { I. Aspectos físicos e } \\
\text { humanos }\end{array}$ & $\begin{array}{l}\text { Nome - Localização - Clima - Índice pluviométrico } \\
\text { - Solo - Microrregião Campos de Guarapuava - } \\
\text { Superfície primitiva - Limites atuais - Distritos - } \\
\text { População - Identidade étnico-cultural - O homem } \\
\text { da roça - Os ícones - Relevo - Hidrografia. }\end{array}$ \\
\hline II. Meio biológico & Vegetação e flora - Preservação do meio ambiente. \\
\hline
\end{tabular}




\begin{tabular}{|c|c|}
\hline Capítulos & Assuntos abordados \\
\hline $\begin{array}{l}\text { III. O espaço vital } \\
\text { humano: o homem } \\
\text { pré-histórico }\end{array}$ & $\begin{array}{l}\text { O Indígena - Usos e Costumes dos Kaingang - } \\
\text { Habitação - Alimentação - Vestuário - Casamento } \\
\text { e Religiosidade - Agricultura - Pecuária - trabalho } \\
\text { - Brincadeiras Infantis - Os funerais - Educação e } \\
\text { Organização Social - O índio tupi-guarani. }\end{array}$ \\
\hline IV. Lendas indígenas & $\begin{array}{l}\text { Lenda da Criação - Lenda do Fogo - Lenda de Naipi } \\
\text { e Tarobá - Resistência Kaingang - Traições, assaltos, } \\
\text { emboscadas - O massacre dos xetás - Principais } \\
\text { líderes indígenas: Guairacá, Pahy, Yongong, Luiz } \\
\text { Tigre Gacon - O legado cultural indígena - Onde } \\
\text { estão os filhos da terra? A Pastoral Indígena e } \\
\text { Indigenista. }\end{array}$ \\
\hline $\begin{array}{l}\text { V. Espanhóis no } \\
\text { centro-oeste } \\
\text { paranaense }\end{array}$ & $\begin{array}{l}\text { Colombo a serviço da Espanha - A reação portuguesa } \\
\text { - A posse espanhola - O Ciclo Encomendero - O } \\
\text { Ciclo Jesuítico - O socialismo cristão guarani - O } \\
\text { Ciclo Bandeirante }\end{array}$ \\
\hline $\begin{array}{l}\text { VI. Expedições ao } \\
\text { sertão do Tibagi }\end{array}$ & $\begin{array}{l}\text { À procura da Serra de Apucarana - Expedições de } \\
\text { reconhecimento do Sertão do Tibagi - A descoberta } \\
\text { de Guarapuava pelos portugueses - A posse da terra. }\end{array}$ \\
\hline $\begin{array}{l}\text { VII. O domínio } \\
\text { português }\end{array}$ & $\begin{array}{l}\text { Diego Pinto de Azevedo Portugal - O Fortim } \\
\text { Atalaia - Freguesia de Nossa Senhora de Belém de } \\
\text { Guarapuava - A Catequese: Padre Francisco das } \\
\text { Chagas Lima - Antonio Rocha Loures. }\end{array}$ \\
\hline $\begin{array}{l}\text { VIII. A saga dos } \\
\text { pioneiros de } \\
\text { Guarapuava }\end{array}$ & $\begin{array}{l}\text { Famílias pioneiras - Indumentária masculina - O } \\
\text { uso da bombacha - A influência platino-rio-grandense } \\
\text { - A garra das pioneiras - Mulheres sesmeiras. }\end{array}$ \\
\hline $\begin{array}{l}\text { IX. Escravidão } \\
\text { africana }\end{array}$ & $\begin{array}{l}\text { A escravidão africana em Guarapuava - A origem do } \\
\text { escravo guarapuavano - vida de escravo - Resistência } \\
\text { e castigo - Abolição da escravatura - Contribuição } \\
\text { cultural africana - Discriminação racial - Belmiro } \\
\text { Sebastião de Miranda - Job de Siqueira Cortes - } \\
\text { Abel Sérgio de Oliveira. }\end{array}$ \\
\hline $\begin{array}{l}\text { X. A expansão } \\
\text { territorial }\end{array}$ & $\begin{array}{l}\text { Colônia do Sacramento - Desbravamento do sertão } \\
\text { do Brasil Meridional - Athanagildo Pinto Martins } \\
\text { - Os campos de Palmas - O Caminho das Missões } \\
\text { - Comunicação com o Sul, com Mato Grosso e o } \\
\text { Paraguai - O Campo do Paiquerê ou Campo Mourão } \\
\text { - Comunicação com a Argentina. }\end{array}$ \\
\hline $\begin{array}{l}\text { XI. Estrutura } \\
\text { Fundiária e evolução }\end{array}$ & $\begin{array}{l}\text { Estrutura fundiária. Evolução econômica: a } \\
\text { pecuária - O ciclo do couro - O tropeirismo - } \\
\text { Estrada das Missões - A importância do tropeirismo } \\
\text { - Saldos positivos do tropeirismo - O cavalo } \\
\text { "guarapuava" - Tradicionalismo - A pecuária de } \\
\text { alta linhagem. }\end{array}$ \\
\hline $\begin{array}{l}\text { XII. Fatores } \\
\text { econômicos }\end{array}$ & $\begin{array}{l}\text { Erva mate - Suinocultura - Setor madeireiro - } \\
\text { A cultura da maçã - Evolução da agropecuária e o } \\
\text { capital financeiro no campo. }\end{array}$ \\
\hline $\begin{array}{l}\text { XIII. Picadas, Trilhas, } \\
\text { Caminhos, Estradas }\end{array}$ & $\begin{array}{l}\text { Trilhas e caminhos - A estrada de rodagem - } \\
\text { Estratégica BR-35 - Rodovia Federal } 277 \text { - } \\
\text { Transportes coletivos intermunicipais - Transporte } \\
\text { coletivo urbano - Transporte ferroviário - } \\
\text { Transporte aéreo. }\end{array}$ \\
\hline $\begin{array}{l}\text { XIV. Os } \\
\text { desmembramentos }\end{array}$ & $\begin{array}{l}\text { Colônia Thereza - Palmas - Problemas sociais do } \\
\text { Contestado e a Guerra dos Peludos e Pelados - } \\
\text { Estado das Missões - Território do Iguaçu - } \\
\text { Emancipação de Prudentópolis - Emancipação } \\
\text { de Foz do Iguaçu - Laranjeiras do Sul - Pitanga } \\
\text { - Palmital - Inácio Martins - Cantagalo - Candoi - } \\
\text { Campina do Simão - Goioxim. }\end{array}$ \\
\hline
\end{tabular}




\begin{tabular}{|c|c|}
\hline Capítulos & Assuntos abordados \\
\hline $\begin{array}{l}\text { XV. Comércio } \\
\text { e indústria }\end{array}$ & $\begin{array}{l}\text { Vendedores ambulantes - A Sociedade Sá, Virmond } \\
\text { \& CIA - O Sítio Santa Maria - Casa Missino - } \\
\text { Marcenaria Ukraína - Ponto Chique e Padaria } \\
\text { Triunfante (hoje mercado) - Casa São José - Casa } \\
\text { Haick - Casa Favorita - Grupo Gelinski - Casa Real } \\
\text { - Pharmácia Amaral - Pharmácia Keche - Farmácia } \\
\text { Trajano - Santa Maria Cia de Papel e Celulose - } \\
\text { Distritos Industriais de Guarapuava. }\end{array}$ \\
\hline $\begin{array}{l}\text { XVI. Bancos oficiais } \\
\text { em Guarapuava }\end{array}$ & $\begin{array}{l}\text { Primeira Casa Bancária de Guarapuava - O primeiro } \\
\text { Banco - Bancos Oficiais: Banco do Brasil e Caixa } \\
\text { Econômica Federal. }\end{array}$ \\
\hline $\begin{array}{l}\text { XVII. A contribuição } \\
\text { dos imigrantes }\end{array}$ & $\begin{array}{l}\text { Colônia guarapuavana - Os portugueses - Africanos } \\
\text { - Franceses - Ucranianos - Poloneses - Austríacos - } \\
\text { Italianos - Alemães - Suábios do Danúbios - Árabes } \\
\text { e sírio - libaneses - Japoneses. }\end{array}$ \\
\hline $\begin{array}{l}\text { XVIII. Cultura } \\
\text { popular- Folclore }\end{array}$ & $\begin{array}{l}\text { Cultura e Folclore - Lenda do Pai Zumé - Lenda da } \\
\text { Princesa Floripes - Lenda do Segredo - Lenda da } \\
\text { Intendência - Lenda da Santa - Lenda da Lagoa das } \\
\text { Lágrimas - Lenda da Cobra com cabeça de dragão - } \\
\text { Lenda do Baile das Feias - Lenda da Capela do } \\
\text { Degolado - Lenda do Fogo Vivo - Lendas acultura- } \\
\text { das - Lendas do Negrinho do Pastoreiro - Lenda do } \\
\text { Saci Pererê - Lenda do Lobisomem - Lenda da Mula } \\
\text { sem Cabeça - As cavalhadas - Os Contos e Profecias } \\
\text { de João Maria - A Dança de São Gonçalo - Romaria } \\
\text { do Divino - Mesada de Anjos - Festas Juninas - O } \\
\text { fandango em Guarapuava - A tropeada - Pratos } \\
\text { típicos - Grupos folclóricos - Suábios do Danúbio } \\
\text { - Grupo italiano Anima - Serse Polski - Odessa - } \\
\text { Sonhos d'Além Mar - Grupo Recreativo Esportivo } \\
\text { Árabe - Grupo Espanhol Ambrujo Andaluy - } \\
\text { Panamérica - Utamaduni - CTG Fogo de Chão - } \\
\text { Laço de Ouro - Orgulho Pampeano - Chaleira Preta } \\
\text { - Encontro da Arte Folclórica. }\end{array}$ \\
\hline $\begin{array}{l}\text { XIX. Evolução Políti- } \\
\text { co-administrativa }\end{array}$ & $\begin{array}{l}\text { Fortim e Presídio de Atalaia - Freguesa de Nossa } \\
\text { Senhora de Belém de Guarapuava - Vila de } \\
\text { Guarapuava - Termo de Guarapuava - Comarca } \\
\text { de Guarapuava - Poderes Legislativo, Executivo e } \\
\text { Judiciário. }\end{array}$ \\
\hline XX. Urbanização & Ruas - Largos - Praças de Guarapuava. \\
\hline $\begin{array}{l}\text { XXI. Saneamento } \\
\text { básico e iluminação } \\
\text { pública }\end{array}$ & Saneamento básico e iluminação. \\
\hline $\begin{array}{l}\text { XXII. Meios de comu- } \\
\text { nicação }\end{array}$ & $\begin{array}{l}\text { Correios - Telégrafos - Telefone - Imprensa escrita } \\
\text { (jornais) - imprensa falada (rádios) televisada. }\end{array}$ \\
\hline $\begin{array}{l}\text { XXIII. Educação - } \\
\text { Recursos culturais }\end{array}$ & $\begin{array}{l}\text { Primeiros professores - Primeiros colégios } \\
\text { particulares - Ginásio Estadual de Guarapuava } \\
\text { (Manoel Ribas) - Escola Normal Secundária "Prof. } \\
\text { Amarílio" - Colégio Agrícola Arlindo Ribeiro - } \\
\text { Núcleo Regional de Educação de Guarapuava - } \\
\text { Secretaria Municipal de Educação e Cultura - } \\
\text { Associação de Pais e Amigos dos Excepcionais } \\
\text { (APAE) - APADEVI - Ensino Particular - Ensino } \\
\text { Superior - Museus - Arquivos e Centro de } \\
\text { Documentação - Usina do Conhecimento - Conselho } \\
\text { Municipal de Preservação da Memória - Casa } \\
\text { Benjamim Teixeira - Academia de Letras, Artes e } \\
\text { Ciências de Guarapuava - Instituto Histórico de } \\
\text { Guarapuava. }\end{array}$ \\
\hline $\begin{array}{l}\text { XXIV. Credos reli- } \\
\text { giosos }\end{array}$ & $\begin{array}{l}\text { Diocese de Guarapuava - Igreja Paroquial Nossa } \\
\text { Senhora de Belém (hoje Catedral do Bispado) - } \\
\text { Igrejas de outros credos. }\end{array}$ \\
\hline $\begin{array}{l}\text { XXV. Clubes sociais, } \\
\text { recreativos esportivos }\end{array}$ & $\begin{array}{l}\text { Guaíra Country Clube - Sociedade Cultural Educativa } \\
\text { Beneficente }\end{array}$ \\
\hline
\end{tabular}




\begin{tabular}{|l|l|}
\hline Capítulos & Assuntos abordados \\
\hline XXVI. Artes cênicas & $\begin{array}{l}\text { Teatro Santo Antonio - Sociedade Dramática “Amiga } \\
\text { do Progresso" }\end{array}$ \\
\hline $\begin{array}{l}\text { XXVII. Artesanato - } \\
\text { artes plásticas }\end{array}$ & Artes plásticas. \\
\hline $\begin{array}{l}\text { XXVIII. Segurança } \\
\text { pública }\end{array}$ & O Degredo - A Guarda Nacional. \\
\hline $\begin{array}{l}\text { XXIX. A polícia } \\
\text { militar }\end{array}$ & $\begin{array}{l}\text { A polícia militar em Guarapuava - 16º Batalhão de } \\
\text { polícia militar - O corpo de bombeiros. }\end{array}$ \\
\hline $\begin{array}{l}\text { XXX. Movimentos } \\
\text { armados }\end{array}$ & $\begin{array}{l}\text { Ataque ao quartel de polícia militar - A guerra do } \\
\text { Paraguai - Revolução Federalista - Revolução de } \\
1924-\text { Ataque do caudilho Leonel Rocha - Revolução } \\
\text { de 193o - A Revolução Constitucionalista. }\end{array}$ \\
\hline $\begin{array}{l}\text { XXXII. Cuidados com } \\
\text { a saúde }\end{array}$ & $\begin{array}{l}\text { Hospitais - Centros Integrados de Atendimentos - } \\
\text { CIAS. }\end{array}$ \\
\hline $\begin{array}{l}\text { XXXIII. Histórico do } \\
\text { cemitério municipal }\end{array}$ & Histórico do cemitério municipal. \\
\hline $\begin{array}{l}\text { XXXIV. A loja } \\
\text { maçônica de } \\
\text { philantropia de } \\
\text { Guarapuava }\end{array}$ & A loja maçônica de philantropia de Guarapuava. \\
\hline $\begin{array}{l}\text { XXXV. O potencial } \\
\text { turístico de } \\
\text { Guarapuava }\end{array}$ & O potencial turístico de Guarapuava. \\
\hline $\begin{array}{l}\text { XXXVI. Memória } \\
\text { Urbana }\end{array}$ & Memória Urbana. \\
\hline $\begin{array}{l}\text { XXXVII. Clubes de } \\
\text { serviço }\end{array}$ & Clubes de serviço. \\
\hline $\begin{array}{l}\text { XXXVIII. Associação } \\
\text { comercial e industrial } \\
\text { de Guarapuava }\end{array}$ & $\begin{array}{l}\text { Serviços Sociais do Comércio e da Indústria - ACIG - } \\
\text { SENAC - SESI - SESC. }\end{array}$ \\
\hline $\begin{array}{l}\text { XXXIX. O escotismo } \\
\text { em Guarapuava }\end{array}$ & O escotismo em Guarapuava. \\
\hline $\begin{array}{l}\text { XL. Símbolos do } \\
\text { município de } \\
\text { Guarapuava }\end{array}$ & Símbolos do município de Guarapuava. \\
\hline
\end{tabular}

Fonte: Marcondes (2010).

Gracita é, também, coautora de seis "obras". Na primeira, foi redatora auxiliada por mais três professores no desenvolvimento da pesquisa. Nas outras cinco, foi coautora juntamente com sua irmã Alcioly Therezinha Gruber de Abreu:

1. "FAFIG, 15 anos de História", publicada em 1985.

2. "Símbolos de Guarapuava", publicada em 1985.

3. "Escravidão e trabalho", publicada em 1991.

4. "O abastecimento de água no século XIX e a evolução do saneamento básico em Guarapuava”, publicada em 1992.

5. “Associação Brasileira de Odontologia e sua trajetória em Guarapuava”, publicada em 1999.

6. "Philantropia Guarapuavana: 150 anos de história", publicada em 2001.

Gracita contribuiu em duas obras realizadas com professores municipais da cidade de Guarapuava/PR, sendo a primeira "Nossa gente conta a nossa História" - Atuou como coordenadora a convite do Prefeito Municipal de 
Guarapuava, Nivaldo Krüger, que conseguiu a publicação pela Imprensa Oficial, sem dispêndio de qualquer recurso. A pesquisa foi realizada, em 1986, por professores de todos os distritos, e os temas foram selecionados pela equipe pedagógica da Secretaria Municipal de Educação, bem como os exercícios que estão no final da obra. A apresentação dessa obra é do Prefeito Municipal de Guarapuava. Foi editada em Guarapuava, e publicada em 1986. E a outra obra chama-se "Em cena: Guarapuava, sua história, nossa vida"; em coautoria com professoras municipais. Publicada pelo Prefeito Municipal Vitor Hugo Burko. Gracita participou, também, do projeto de levantamento dos arquivos de Guarapuava realizado pela FAFIG, publicado, em 2004, pelo Boletim $n^{0} 24$ do Departamento de História da UFPR.

Em sua narrativa, a entrevistada faz algumas observações sobre as obras que considera de extrema importância:

1. As obras de minha autoria e aquelas das quais participei como coautora são todas de cunho paradidático e abordam todas as camadas sociais que contribuíram para o desenvolvimento de Guarapuava, sem distinção de cor, raça, credo ou posição social. E como todo o texto histórico tem uma função social, os livros apresentam problemas que desenvolvem o senso crítico do leitor.

2. Incontestavelmente, não são histórias apologéticas em relação a Guarapuava, porque descrevem somente a realidade.

3. Não são histórias elitistas ou regionalistas que defendam Guarapuava como separatista - que descrevam algo que aqui não existe e apresentem o guarapuavano como um herói (melhor que outros); mas, colocam sim, em evidência aqueles que conseguiram méritos com seu esforço ou foram punidos por seus erros.

4. Não apresentam uma batalha do tradicional contra o novo, porque registram todos os acontecimentos e as realizações desde a descoberta destes Campos em 1770 até 2010, quando o município comemorou 200 anos da chegada da Real Expedição

5. Também não são excludentes, porque descrevem a contribuição cultural do índio, do escravo africano, de quatro ou cinco degredados que prestaram bons serviços. As obras descrevem igualmente a contribuição cultural dos imigrantes portugueses, franceses, ucranianos, poloneses e austríacos, italianos, alemães, suábios do Danúbio e japoneses.

6. Fazem lembrar daquilo de belo e importante que aqui existe ou foi realizado - a região serrana, com clima de estância e até neve; as belezas e riquezas naturais; o trabalho das famílias pioneiras que desenvolveram a pecuária e o tropeirismo; fundaram povoados e vilas anexando $175.000 \mathrm{~km}^{2}$ ao 
território brasileiro, cuja área foi fator importante para a nossa unidade e soberania nacional.

7. Relembram as instituições culturais, artísticas, esportivas; os credos religiosos, o progresso da agropecuária, do comércio e da indústria; o folclore com a lenda da Santa Padroeira, a tradição, a evolução social, política e administrativa, os movimentos armados; enfim, o trabalho de todos quantos aqui se radicaram e contribuíram para que Guarapuava chegasse até aqui, com o nível de cidade de porte médio que hoje possui.

8. Todo o conteúdo está fundamentado em fontes fidedignas, com sérias pesquisas, $e$ sem qualquer pretensão ideológica ou a intenção de agradar esta ou aquela autoridade ou dirigente. Visa tão somente o resgate da identidade e da nacionalidade, que nos fazem sujeitos de nossa própria História. Também é indiscutível que a autoestima é a condição sine qua non que anima o indivíduo a trabalhar com amor, defender e fazer progredir aquilo que considera seu: a família, o lar, o seu pedaço de chão, o município, o estado e a nação, pois ninguém ama aquilo que desconhece.

9. Portanto, o conhecimento da história (identidade), por ser fundamental para a autoestima, fará germinar o civismo, e este garantirá que continuaremos como nação livre, defendida por seus filhos, e seremos hoje e sempre brasileiros, paranaenses $e$ guarapuavanos de coração.

Gracita apresentou artigos referentes à História de Guarapuava em oito edições na Revista Monjolo, bem como nos jornais da época. Também apresentou uma pesquisa sobre a Cultura Arquitetônica e Urbanística no IV Simpósio Americano, organizado pela Pontifícia Universidade Católica do Paraná (PUC-PR), em Curitiba.

\subsection{Participação em projetos e premiações}

Conforme relatos anteriores, a vida profissional de Gracita foi muito ativa. Dentre suas várias atividades, foi conferencista do $1^{\mathrm{o}}$ Congresso Tradicionalista Gaúcho, de nível internacional, realizado em 1984, na cidade de Guarapuava, como também responsável pela organização da parte histórica do desfile comemorativo dos 150 anos de Guarapuava e do desfile do Sesquicentenário da Independência do Brasil.

É, também, sócia-fundadora do Conselho da Preservação da Memória; da Academia de Letras; Artes e Ciências de Guarapuava; do Instituto Histórico de Guarapuava e da Associação dos Professores Aposentados (ADAU), da UNICENTRO.

Recebeu, como reconhecimento por seu trabalho, os seguintes títulos: 
1. Cidadã honorária de Guarapuava, concedido pela Câmara Municipal, em 1986.

2. Professor Emérito da UNICENTRO, concedido pelo COU/UNICENTRO em 1988.

3. Comenda Duque de Caxias, conferida pelo Grande Oriente do Brasil, Paraná, em Curitiba, 2004.

4. Comenda da Ordem do Pelicano, conferida pelo Grande Oriente de Guarapuava, 2004;

5. "Escritora guarapuavana", conferido pelo Rotary Club Guarapuava, Distrito 4640, em 2005.

6. Personalidade destaque no último século do milênio, em Guarapuava, título conferido pelo Colégio Aliança, em 1990.

7. Diploma de Mérito Cultural, conferido pela Academia de Letras, Artes e Ciências de Guarapuava, em 2010.

8. Prêmio "Visconde de Guarapuava", conferido pela Revista VISUAL, em 2013.

9. Certificado de Mérito Cultural, conferido pelo Instituto Histórico de Guarapuava, em 2014.

\section{5 À GUISA DE CONCLUSÃO}

É surpreendente a quantidade de pesquisas que a autora realizou para reconstruir a história de Guarapuava-Paraná, comprovadas pela quantidade de obras publicadas de sua autoria e em coautoria. A responsabilidade de registrar e dar sentido à história de Guarapuava, pela historiadora, institui-se na forma de reunir, em acervo particular, fotografias, livros, revistas, jornais e documentos.

Nesse sentido, a professora Gracita contribuiu para preservar a história da memória da cidade de Guarapuava. E esse acervo documental promove a difusão cultural, possibilitando que estudantes da rede de ensino possam usufruir do legado histórico da cidade.

Foi verificado, conforme as evidências das narrações de Gracita, que se trata da história de uma professora que iniciou a sua carreira profissional com apenas 14 anos e, embora fosse uma adolescente, teve maturidade e responsabilidade para com as questões de ensino. Ainda jovem, recorria à sua mãe, Olympia, que era professora, para ser orientanda sobre didática em sala de aula. Quando Julia (2001) relata sobre a pesquisa realizada na França, em que houve o desejo compartilhado pela escola entre pais e filhos, que permitiu ascensão social em direção à profissão muito dignificada do professor, esse acontecimento tem muita semelhança com a história de vida da professora Gracita.

Outro ponto foi sua dedicação ao ensino, tendo em vista que uma aula ministrada não é simplesmente um repasse de conteúdo; porém, enfatiza que o conteúdo apresentado aos alunos deve ser acompanhado de uma história, como maneira de dar significado ao que está sendo proposto.

A vida profissional de Gracita, relatada por meio das entrevistas, oportuniza que se compreendam as etapas de sua trajetória de forma detalhada, como o exemplo da 
"inquietação da aluna sobre o significado do nome de Guarapuava", que não somente motivou mas também foi o marco de sua vida como historiadora e escritora. Na obra "200 anos de uma Caminhada Histórica 1810-2010”, encontra-se a resposta da originalidade ao significado da história de Guarapuava, em vasta pesquisa, por meio de investigações cronológicas que fazem parte de seu acervo bibliográfico.

Considerando que a história oral é repleta de desafios, é necessário ter a ordem das experiências narradas. Nóvoa (1995) revela alguns objetivos para se entender o percurso de vida do professor, que são a representação do que foi a formação, o processo de formação e as interações entre espaços profissionais e outros espaços. Gracita cumpre essa missão, porque foi possível adentrar na história de sua vida e compreender essas etapas, conforme os seus relatos e apresentação de suas obras.

Dessa forma, compreender a história de vida de Gracita Gruber Marcondes possibilita que esta seja vista como um sujeito vivo, permitindo examinar o repertório da sua vida como professora a partir de um cenário educacional dinâmico, no qual se escreve uma história que pode ser analisada, ampliada ou, até mesmo, confrontada, pois esse é um dos sentidos de historiar.

\section{REFERÊNCIAS}

ALBERTI, Verena. Manual de história oral. 3. ed. Rio de Janeiro: Editora FGV, 2005.

CHARTIER, Roger. A história cultural: entre práticas e representações. Lisboa: Difel, 1990.

JULIA, Dominique. A cultura escolar como objeto histórico. Revista Brasileira de História da Educação, Campinas, n. 1, p. 9-43, jan./jun. 2001.

LE GOFF, Jacques. História e memória. 5. ed. Tradução de Bernardo Leitão. Campinas: Editora da UNICAMP, 2003.

LIMA, Antônio Fernandes Costa; GUALDA, Dulce Maria Rosa. História oral de vida: buscando o significado da hemodiálise para o paciente renal crônico. Revista da Escola de Enfermagem da USP, São Paulo, v.35, n. 3, p. 235-24, 2001.

MARCONDES, Gracita Gruber. 200 anos de uma caminhada histórica (1810-2010). Guarapuava: O Autor, 2010.

NÓVOA, Antonio et al. (Org.).Vida de professores. Porto: Porto Editora, 1995.

THOMPSON, Paul. A voz do passado: história oral. 2. ed. São Paulo: Paz e Terra, 1992. 